\title{
The Analysis of Coordinated Development between Land Intensive Use and Land Ecological Security: A Case of Chengdu City
}

\author{
Wei-zhong Zeng (Corresponding author) \\ College of Economic \& Management, Sichuan Agricultural University \\ No.46 Xin Kang Road, Ya'an, 625014, China \\ Tel: 86-139-0816-0293, 86-835-288-2728Ｅ-mail: auldkgk@sicau.edu.cn, Pangxiaoming222@163.com \\ Li Li, Xi Cai \& Cheng-yi Huang \\ College of Economic\& Management, Sichuan Agricultural University \\ No.46 Xin Kang Road, Ya'an, 625014, China \\ Tel: 86-151-8121-5210 E-mail: lilibamboo@yahoo.cn;sunmily@yahoo.com.cn \\ The paper is financed by Key Project of the National Eleventh-Five Year Research Program of China. \\ No.2006BAJ05A13(Sponsoring information)
}

\begin{abstract}
This study has been performed in order to analyze the coordinated degree and evolving trends of the land intensive use and land eco-security based on the statistical data from 1998 to 2007 in Chengdu city by Synergetios theory and dynamic coordinated degrees model. Results show that during the study period, the level of land intensive use and land ecological security both rose in Chengdu, the former continuing to raise, the overall increasing but some fluctuations in the latter. Dynamic coordinated degree in 10 years is between $8.99^{\circ} \sim 57.71^{\circ}$ with a trend of rising firstly then dropping, undergoing the process from a relatively harmonious development to the best coordinated development, then to less coordinated development. From 2005, the coordinated degree between the two systems began to decline.
\end{abstract}

Keywords: Urban land intensive-use, Urban land ecological security, Coordinated degree

\section{Introduction}

China set off an upsurge of urban land intensive use since the 90's of 20th Century. Since China is in the period of transformation of social economy, land intensive use is often one-sided pursuit of inputs and outputs to maximize, ignoring land eco-system carrying capacity. Urban land intensive use is one of the major causes of land ecological security system changes and exert a significant pressure on it, such as land pollution, land deterioration and weakening or even loss of ecological function of land to affect urban land sustainable development. Urban land intensive use and urban land ecological security are a complicated antinomy unity, because the more intensive land use is, the higher the efficiency is, the more likely the land adversely affects the land ecological environment (Jing Wang and Xiao-mei Shao, 2008). Only if coordinating the relationship between urban land intensive use and urban land ecological security, it is more likely to achieve urban land sustainable development and sustainable development of human society. Therefore, there is a realistic significance for regional land sustainable use in studying on the coordinated degree between urban land intensive use and urban land ecological security.

Regard to urban land intensive use and urban land ecological security, at present, little research exists on the combination between land intensive use and land ecological security, but a number of studies exist on the each subfield. A large body of research exists on urban land intensive use and land ecological security from qualitative analysis, but little research is from the quantitative point of view. Overseas researches have focused on the ecological concept throughout the course of land use, in which urban land use eco-school(Chapin F. S. and Kaiser E. J.,1967; Sheng-he Liu and Jianmin Zhou,2001) is the most representative school, whose research focused on urban planning(Cheng-long Dan and Qun Wang,2002), land-use control(Ye Cheng et al.,2003), agricultural land protection(Xian-wen Li and Pei Lin,2001; An-lu Zhang,2000) as well as sustainable land use(1993), etc.

Chinese scholars have also studied on eco-environmental problems in the process of land intensive use. For example, Xiu-ru Dong et al.(2006)deem that the reasonable land intensive use can promote the improvement of ecological environment, sustainable land use requirements the combination of intensive land use and improving the ecological environment. Some scholars think that urban land intensive use not only pursuits land output benefit, but also pays attention to avoid ecological environment deterioration on the point of view of the theory of urban sustainable development. Hong-ming Luo (2004) hold that the consistency between expansion of urban space and eco-system carrying capacity is a requirement of urban land intensive use. Xin-wei Liu et al. (2006) say that the connotation of urban land intensive use is to achieve the comprehensive benefits of economy, society, resource and ecology at the same time to improve land use efficiency. There is a rational limit during the course of urban land intensive-use, not the more intensive put into, the better the result is.

The hot point of the research is to set up the indicators reflecting the land sustainability and eco-environmental 
benefits to evaluate the overall level of urban land intensive use, but the results only represent the overall land use intensity level, which could not further reflect deeply whether the level of urban land intensive use is coordinated with land ecological security level. Xiao-yan Wang et al. (2008), Ge Song et al.(2008) set up indicators reflecting the land sustainability and eco-environmental benefits to evaluate the overall level of city land intensive use. In order to reveal the interior coordination among the indicator system, Jin-tao Li et al.(2009)evaluate the level of urban land intensive use in Hubei province by DPSIR model, but the results only reflected the coordination between indicators simply, which could not further reflected the degree of coordination, as well as dynamic change trend.

In order to identify the coordinated development level between urban land intensive use and land ecological security system, we take Chengdu City--the higher land intensive use level in Southwest China as the example, supported by the synergistic theory, systems theory and dynamic coordination degrees model. At last, we provide decision-making reference for the policy of coordinated development, promoting the sustainable and coordinate development between urban land intensive use and land ecological security system.

\section{Materials and methods}

\subsection{Theoretical Foundation}

In 1971, Hermann Haken, German physicist, proposed Synergetios theory, who deemed that system's transition process is decided by system control parameters and achieved through the self-organizing of internal system, at the same time the synergy of internal parameters when system is in the critical zone decide what kind of sequence and structure of the system go towards(Yao-bin Liu,2007).System's organizing is a dynamic development process that subsystems and system elements are interaction and mutual restraint(Yao-bin Liu,2007).

The coordination of systems is the function of each part of the system is developing towards positive direction at a reasonable portion in time and regionally, in which the system turns from disorder to order to achieve a good harmonious state between subsystems and system elements(Yao-bin Liu,2007).From the viewpoint of system, city land intensive use system and land ecological security system are interaction to built a compound system of 'land use--ecological safety', which have internal requirements of coordination in the process of interaction.

Coordinated degree is the harmonious degree of subsystems and system elements. From Synergetics we can know that coordinated degree of order parameter of internal system decides the tends from disorder to order(Yao-bin Liu,2007).Coordinated degree of urban land intensive use system and land ecological security system is coordinated state between regional land intensive use and land ecological safety in different stage of land intensive use. Land ecological security level differ greatly in the degree in which different land intensive use level affects it and land ecological safety system has its own variation, so coordinated degree is characterized by dynamic evolution. In order to analyze the changeable tends in a given time period, we choose dynamic coordinated degrees model based on Synergetios theory.

System dynamic coordinated degree model represent the character of changeable time, depicting dynamic variation among several subsystems with the character of system dynamic modeling (Yao-bin Liu, 2007). It is simple and convenient to apply. But it is difficult to give more information elaborately. Therefore, it is an available and practical method to understand if two systems are coordinated (Guo-wei Wang, 2000).

\subsection{Research Approach}

Dynamic coordinated degrees measure that the development trend and degree of the whole systems' coordinated degrees at a given time series with the feature of dynamic modeling of systems. Taking urban land intensive use system and land ecological security system as a compound system, according to general system theory (Bertalanffy LV, 1987), the speed of evolution of this compound system is

$$
V A=\frac{d A}{d t}, V B=\frac{d B}{d t}
$$

$\mathrm{A}$ is land intensive use system, $\mathrm{B}$ is land ecological security system, $\mathrm{t}$ is time, and the speed of evolution of this compound system--V can be seen as a function of $\mathrm{V}=\mathrm{f}(\mathrm{VA}, \mathrm{VB})$. We could study dynamic coordinated relationship of the whole compound system and this two subsystems. A coordinated system based on variables of VA and VB was built and variational track of V is a oval in this coordinated system. From graph 1 we can see that the included angle of VA and VB is

$$
\alpha=\underset{V B}{\operatorname{arctg}}
$$

In an evolutionary cycle, the whole system is divided into four phrase(Biao Qiao and Chuang-lin Fang,2005), when $-90^{\circ}<\alpha<0^{\circ}$, the whole system is in the low-grade symbiosis stage, in which land intensive use strength is less thus land ecological carrying capacity is big. When $0^{\circ}<\alpha<90^{\circ}$, the whole system is in the coordinated development stage, land intensive use system and land ecological security system are beginning to interact and common development. When $\alpha=45^{\circ}$, this two system are most, coordinating, when approaching to $0^{\circ}$ or $90^{\circ}$, the systems are less coordinating. When $90^{\circ}<\alpha<180^{\circ}$, the whole system is in the limited development stage, 
land ecological environment deterioration and the extent of land intensive use will be limited ,this two contradictions have become increasingly prominent, and intensified, eventually leading to the disintegration of the system. When $-180^{\circ}<\alpha<-90^{\circ}$, the whole system is in the revival stage, land intensive use system and land ecological security system are in bad condition. The old system collapsed and the new system is regenerating.

\subsection{General Situation of study area}

Chengdu, as an important central city in the west of China, is the radiant point and headquarters of the Development of Western Regions, being a nationally advanced clean city, where the area of Demonstration Zone of Ecology accounts 81.1 percent of area of Chengdu. Chengdu has jurisdiction over nine District, four City (county-level city), six Counties, the total catchments' area of 1.239 square kilometers, where is thickly peopled with 2310 persons / sq km in 2007.This research takes the Central Region of Chengdu as its object, including Jinjiang District, Jinniu District, Wuhou District, Qingyany District, Chenghua District, Longquanyi District, Qingbaijiang District, Wenjiang District and Xindu District.

\subsection{Data Sources}

The data resources of this paper come from statistics published by the census and statistics department, including Urban Statistical Yearbook of China, Sichuan Statistical Year Book, Chengdu City Year Book, Regional Economy Statistical Yearbook of China from 1999 to 2008 and related data from land departments and urban construction sector, replenishing by the official website of the statistical data to guarantee the data integrity and authoritativeness.

\subsection{Building index system of evaluation}

In this paper, from the function mechanism of interactive coercing relation of land intensive use and land ecological security, based on Synergetic theory, according to a holistic, scientific, hierarchy and feasibility of the principle, referring to 'China's sustainable development resources study (2005)' published by the Ministry of Land and Resources Information Center(Land and Natural Resources Information Center,2006)and related research(Lu-hong Zhou, et al.2009; Tian-ming Zhu et al.2009; Bang-Xiong Xie, et al.2009; Hui-yong Wang, et al,2007),visiting and comprehensive feedback from the experts, the reality of studying region and research purpose, evaluation index system of urban land intensive use and land ecological security was established. Urban land intensive utilization levels are determined mainly by the level of inputs for land use, land use degree and land use efficiency, specifically including seven indicators. Urban land ecological security levels are determined mainly by the Pressure - State - Response conceptual model, establishing three levels of nine indicators, and trend indicators are divided into positive and negative indicators of trends. Area of Gardens and Green Area, green zone coverage are positive indexes, which show that the greater the value is, the better the security situation in the land ecosystem is. Per square kilometer the urban industrial three wastes emission is negative indexes that explain the greater these indexes are, the greater the land pressure is, the worse the land ecological security situation is (Table 1).

\section{Results}

\subsection{Measurement and analysis of land intensive use and land ecological security}

This paper comprehensively evaluates the level of urban land intensive use and land ecological security though factor analysis method. In order to eliminate the effects of different dimensionless variables, the standard deviation method is used to standardize the sample data. The composite scores of land intensive use level and land ecological security level in Chengdu from 1998 to 2007 is as follows (Table 2).

Comprehensive evaluation results of the system are only the relative level of the whole evaluation period of the year, which can be either positive or negative. When the result is negative, it shows that the level of development of this year is lower than the average level of development within the study period. Comprehensive evaluation results demonstrate that the level of land intensive use and land ecological security in Chengdu both rose, the former continuing to rise, but some fluctuations in the latter and beginning to fall from 2005(Graph 2).

In accordance with the mutual coordination between the two mechanisms it can be divided into three stages. The first stage, from 1998 to 2000, the level of land intensive use and land ecological security both rose before 1999, and the development trend of this two systems is consistency. But after 1999, the level of intensive land use and land ecological security show the opposite trend, land intensive use and land ecological security demonstrate the role of a minor antagonist, in 2000 this two levels are almost flat. The second stage, from 2000 to 2005 , the level of land intensive use and land ecological security increased in the setback, and in 2005 this two levels are almost flat, too. The third stage, from 2005 to 2007, the level of land intensive use continue to grow, but the level of land ecological security begin to drop, the gap has been continuously widened, the level of land intensive use has achieved the highest point, thus the level of land ecological security has decreased blow the level in 2005.

\subsection{Measurement and analysis of dynamic coordinated degree}

In order to adequate disclosure the coordinated state of land intensive use and land ecological security in Chengdu from 1998 to 2007,this paper studies on the coordinated relationship by dynamic coordinated model. According to this model, evolution equations of urban land intensive use and land ecological security are 
established as followed,

$$
\begin{aligned}
& X=-0.621+0.002 t^{3} \quad \mathrm{R}^{2}=0.847, \quad \mathrm{~F}=44.288 \\
& Y=-0.749+0.019 \mathrm{t}^{2} \quad \mathrm{R}^{2}=0.923, \mathrm{~F}=96.093
\end{aligned}
$$

Equation $\mathrm{X}$ and $\mathrm{Y}$ are fitted equation to time of urban land intensive use and land ecological security. $\mathrm{X}$ is the level of city land intensive use, and $\mathrm{Y}$ is the level of land ecological security. Both of them have been subjected to examination and fitting for the 0.05 significance level test. Equations are significantly meaningful. By formula (1) (2) calculating the dynamics of the coordinated degree of urban land intensive use and land ecological security, the results are in the following table (Table 3).

According to synergy theory and dynamic coordinated degree model, when the coordinated degree is $45^{\circ}$, this two systems are most harmonious, but the systems are less harmonious approaching to $0^{\circ}$ or $90^{\circ}$. Because of multifactor synthetic effects of policy, infrastructure and urban construction, dynamic coordinated degree in 10 years is between $8.99^{\circ}$ and $57.71^{\circ}$ with a trend of rising firstly then dropping, showing three kinds of track record.

The first stage, from 1998 to 2002, coordinated degree of land intensive use and land ecological security increased from $8.99^{\circ}$ in 1998 to $38.35^{\circ}$ in 2002 . This class has the most significant change in Chengdu, undergoing from less coordination of state to relatively coordination of state. This result is partially explained by emphasizing on city-size extension blindly but ignoring the content of tapping the potential expansion, urban land was severely extensive used, leading to a lower level of urban land intensive use but land eco-environment capacity is large. In 2002, the level of urban land intensive use is still lower than the level that urban ecological safety system requires, which are coordinated developing when the level of urban land intensive use is in the range of the urban land ecological security could stand. There is still room for improving urban land intensive use at the condition of less fluctuation of land eco-environment capacity.

The second stage, from 2003 to 2004 , the coordinated degree is between $43^{\circ}$ and $50^{\circ}$. Because the coordinated degree is $45^{\circ}$, the two systems are most harmonious, the two systems achieve their highest level in this phrase, being in a state of sustaining, stable and the best coordination in a decade. Within this period, with the hot real estate market continuous improving in Chengdu, a purely commercial and purely residential development projects began to rise. From 2003 to 2004 the level of land intensive use increase was as high as $29 \%$, indicating that with the intensity of land development gradually improved, levels of urban land-intensive use were rising. At the same time, implementation of industry structure's adjustment in East Chengdu Suburb Industrial District made the entire city eliminating 288 clay brick factory and 1311 high water consumption and high pollution enterprises had been closed, stopped, turned and moved. A series of measures of Chengdu in urban ecological security construction helped to improve the level of ecological safety of urban land, to promote the sustainable development of Chengdu with a profound effect, making the level of intensive use of urban land and land ecological safety level of coordinated development in 2003-2004.

The third stage, from 2005 to 2007 , the coordinated degree increase from $51.69^{\circ}$ in 2005 and to $54.92^{\circ}$ in 2006 and to $57.71^{\circ}$ in 2007 . When the coordinated degree approaching to coordinated degree $0^{\circ}$ or $90^{\circ}$, the systems are less harmonious, so this period is from the state of the best coordination to less coordination. In this period, urban land eco-environment faced with tremendous pressure, industrial pollution was very serious, and pollution of urban life was increasing. Due to the continuous increasing of land intensive use, while neglecting the status of land ecological security, the urban land ecological security carrying capacity demonstrate the role of antagonist the land intensive use, leading to a lower level of overall coordination between the two system. The developmental speed of land intensive use systems is slower than speed of land ecosystem changes, indicating that the coordinated development of two systems is inconsistent. It can be predicted that in the next few years, urban land ecological security on their ability to support land intensive use will gradually weaken, land ecological security issues will limit the level of intensive use of urban land to increase. Therefore, to alleviate the ecological pressure on land and improve the level of ecological safety of urban land, coordinating intensive use of urban land and land ecological safety will be one of the future priorities of urban construction of Chengdu.

\section{Discussion}

As a result of multifactor synthetic effects of policy, infrastructure and urban construction, there are six major elements affecting the coordinated degree between urban land intensive use and land ecological security in Chengdu.

Firstly, land use economic effectiveness factors including public finance expenditure per square and investment in fixed assets per square play an important role for coordinated development between urban land intensive use and land ecological security. Public finance expenditure per square of Chengdu is only $721662 \mathrm{Yuan} / \mathrm{km}^{2}$ in 1998, but in 2007 it has achieved to $8043664 \mathrm{Yuan} / \mathrm{km}^{2}$. It increased more than 11 times. Investment in infrastructure in Chengdu has increased from 201.3 billion Yuan in 1998 to 961.8 billion Yuan in 2007, which grown 4 times, real estate development and investment is 909.9 billion Yuan in 2007, which is 11 times than in 1998, renovation and reformation investment is 506.5 billion Yuan, which is 10 times compared with 1998. The 
increase of investment in fixed assets directly contributed to the improvement of intensive land use. But we could find that intensive land use in Chengdu is extension and expansion development, inadequate to excavate inside potentiality. Meanwhile, environmental investment in Chengdu was just 215 billion Yuan between 2001 and 2005, 378.7815 billion Yuan between 2005 and 2010, which was much lower than investment in infrastructure, real estate development and investment, renovation and reformation investment. Condition for investment is a restricted factor in enhancing the level of land ecological security in Chengdu. The unbalance investment between intensive land use and land ecological security cause the inconsistent development between them.

Secondly, infrastructure drivers such as construction area per person and road area per square are the critical matter of land intensive use. In the period 1998-2002, construction area per person in Chengdu increased by $7 \%$, high density residence project is relatively less, so the level of intensive land use is low. With the rapid development of industrialization and urbanization of Chengdu, the rapid expansion of urban construction land, area of construction land in 2007 was far more in relative terms than it was in 1998 and increased by $10 \%$ compared with 2006. Road area per square has increased by $3 \%$ in recent decades. Infrastructure factors drive the development of intensive land use. At the same time, project of Chengdu Fu-Nan River Conservancy and Comprehensive Regulation Works of Sha River drove the ecological environment construction of the whole city. These infrastructure drivers affect the coordination degree between urban land intensive use and land ecological security directly.

Thirdly, Chengdu is the one of highest population density city in China. In 2007, it is 2310 people / sq km. The highest population density will produce a large mount of domestic waste and cause other environment problems. So the population density is a key factor to affect land sustainable use. But there is less control population density policy in Chengdu. Over-population makes great press to land and threaten the coordinated development between urban land intensive use and land ecological security. Population pressure is large, in 2007 average daily flow of more than 200 million and of which about 1.12 million transient population, coupled with its high-density resident population, urban land has been seriously beyond a reasonable burden on the environment.

Fourthly, Area of Gardens and Green Area, Green zone coverage will promote the land ecological security level so as to improve land use sustainable development. Green cover rate in Chengdu built-up area grew from $20.6 \%$ in 1998 to $36.1 \%$ in 2004 and to $38.09 \%$ in 2007 , which is far less than $50 \%$ that Ecological and environmental protection organizations in United Nations set. Area of Gardens and Green Area per person increased from 3328 (hectare) in 1998 to 14495 (hectare) in 2007, which has been grown by 4 times. And Green zone coverage in 2007 is 1.8 times than in 1998. In 2003, project of Chengdu two rivers city forest park carried out. Qingbajiang District returning land to river bank protection forest is 500 Acres, afforestation is 840 Acres, forest conservation is 700 Acres(Sichuan Yearbook, 2003). All thee measures will improve the level of land ecological security so as to advance the coordinated development between land intensive use and land ecological security.

Fifthly, volume of industrial waste water up to the discharged standards per square kilometer and volume of waste water discharged are reversal driving factors, which affect land ecological security level mostly. There are more than $80 \%$ of the whole rivers in Chengdu that is slight and severe pollution. Due to the limit of public finance and the intake water of Dujiang Dam, the improvement of water quality by Chengdu Fu-Nan River and Sha River Conservancy and Comprehensive Regulation Project is very little. Exiting section with the water quality did not attain a designated standard, and water quality situation of urban concentrated drinking water sources land just reached a periodical position. In the meantime, the Combined Sewer System in urban drainage pipe network systems become bottleneck that restricts improvement of urban water environment, affecting land ecological security of Chengdu City (Xiao-bo Yang, 2008). Wastewater discharge of Chengdu in 2007 increased by $2.6 \%$ compared with 2006. In order to solve the pollution of urban rivers in Chengdu, 'Comprehensive Environment Renovation Planning of Chengdu Urban Region' was given by government of Chengdu. Though the effort of local government, volume of industrial waste water up to the discharged standards per square kilometer and volume of waste water discharged undergo an upward trend firstly then downward slightly, which promote the coordinated development between urban land intensive use and land ecological security in Chengdu.

Lastly, along with the increase of private car in Chengdu and misconduct of polluting enterprises, per square kilometer volume of industrial waste Gas emission has been raised from 57465 standard cubic meters per hectare in 1998 to 104577 standard cubic meters per hectare in 2007. Per square kilometer volume of industrial waste Gas emission contribute one major factor to land ecological security. In $2005, \mathrm{SO}_{2}$ emission of Chengdu was 15.54 ten thousand tons per year, volume of soot discharged was 18.23 ten thousand tons per year, and volume of dust discharged 3.26 ten thousand tons per year. Total emission of pollution exceeds carrying capacity of urban environment in the most places in Chengdu (Environment Protection Bureau of Chengdu, et al. 2005). In 2006 the air pollution styles in Chengdu are changing from single coal-burning pollution to mixed pollution of coal-burning pollution and vehicle pollution. The same year Environment Protection Bureau of Chengdu laid down several files including 'Announce of Control Coal Combustion and $\mathrm{SO}_{2}$ Pollution' to strengthen the supervision power of Coal-fired Enterprise, closing sources of contamination such as Chengdu Thermal Power Plant, adopting technology of keeping sulphur of briquettes to control high sulphur coal contaminating urban 
area. But, air environmental quality index of Chengdu still ranked the province's last one in 2006(Report on the State Environment in Chengdu, 2006). In 2007, a series of atmospheric environments compositive renovation measures including closing Huaneng Power Plant, Separating Sulfur from Flue Gas and Dust Jialing Power Plant of Chengdu, Strengthening treatment of raise dust, relieving urban automobile pollution and artificial precipitation(Report on the State Environment in Chengdu,2007) was carried out. These measures count for a good deal in improve the level of land ecological security so as to further the coordinated development between intensive land use and land ecological security.

\section{Conclusion}

This paper analyses the level of urban land intensive use and land ecological safety from 1998 to 2007 in Chengdu through Synergy Theory and Coordinated Degree Model, the main conclusion is as follows,

1) Between 1998 and 2007, the level of land intensive use and land ecological security both rose in Chengdu, the former continuing to raise, the overall increase but some fluctuations in the latter. So land ecological security issues should be paid more attention, otherwise the level of land ecological safety will continue to decline.

2) Dynamic coordinated degree in 10 years is between $8.99^{\circ}$ and $57.71^{\circ}$ with a trend of rising firstly then dropping, undergoing the process from a relatively harmonious development to the best coordinated development, then to less coordinated development. In 2005, the degree of coordination between the two systems began to decline, which was in agreement with the reality of land intensive use and pressure on land ecological security. It demonstrates that the study by Synergetios theory and dynamic coordinated degrees model is operability and reasonability. With the rising levels of urban land-intensive use, the level of ecological safety of urban land in Chengdu has been shown a downward trend. Therefore we must pay attention to the ecological environment construction in Chengdu, otherwise the deteriorating ecological environment will impeded, restrict the development of land intensive use, which may eventually develop into less coordination stage.

In addition, the analysis in this paper does not represent the absolute level of coordinated degree, but relative level. Further research into the main problem of the temporal and spatial analysis as well as index system optimization will follow. The approach discussed in this article has developed and applied practical methods for coordinating the land intensive use and land ecological security so as to achieve land sustainable use (not only for Chengdu City). The study combines land intensive use and land ecological security, bridging scientific discussion and practice by applying Synergy Theory and Coordinated Degree Model, presented quantitative explicit approach to highlight interactions among intensive land use which hamper or stimulate land ecological security. The methods discussed are transferable to other studies and regions of coordinated development and sustainable development. However, for land ecological security evaluation, the selection of indicators has to be updated dependently with the climatic and natural conditions of the new regions.

\section{References}

An-lu Zhang. (2000). Policies and Measures to Protect Farmland in U.S. World Agriculture, Vol, $249,8 \sim 10$.

Bang-Xiong Xie, Zi-biao Cheng, Nai-ping Song. 2009. Analysis on Intensive Use of Land in the Urbanization Process of Mianyang City. Journal of Sichuan University of Science \& Engineering(Social Sciences Edition, Vol,24,64-67.

Bertalanffy LV. (1987). General system theory-foundation, development applications (Reversion edition). New York: George Beaziller.

Biao Qiao, Chuang-lin Fang. (2005). The dynamic coupling model of the harmonious development between urbanization and eco-environment and its application in arid area. Acta Ecologica Sinica, Vol ,25, 3003 3009.

Bo Zhang. (2007). Research on the Evaluation of Urban Land Resources Intensive Utilization Based on The Theories of Synergetics. Dalian University of Technology.

Chapin F S, Kaiser E J. (1967). Urban Land Use Planning (3rd edn.).University of Illinois Press.

Cheng-long Dan, Qun Wang. (2002). Comparison of Land Planning Between China and The West. China Land Science, Vol, 16,43 47.

Dan-yan Xu, She-tian Qu, Xiang-nan Liu. (2004). Land Intensive Use Research for Industries Development of the Areas Adjacent to the Yangtse River Jiangsu Province as an Example. Journal of Nanjing University of Finance and Economics, Vol,3,37-40.

Environment Protection Bureau of Chengdu. (2007). 2007 Report on the State Environment in Chengdu.pp1, 11. Environment Protection Bureau of Chengdu. (2006). 2006 Report on the State Environment in Chengdu, pp1, 10. Environment Protection Bureau of Chengdu et al. (2005). Chengdu City the 11th Five-Year plan on environmental protection.

Food and Agriculture Organization of the United Nations. (1993).FESLM:An International Framework for Evaluating Sustainable Land Management, World Soil Resources Report 73.

Ge Song, Wen-ya Zhang, He Ma. (2008). Construction and Evaluation of Intensive Land Use Indicator System 
during Transition Period of Forest Industry City: A Case of Yichun City in Heilongjiang Province. China Land Science, Vol,22,31-38.

Guo-wei Wang. (2000). Study on Coordinated Development Theory and Methods. Beijing, China's Financial and Economic Press, pp220.

Hong-ming Luo. (2004). The Intensive Distribution Model and the Choice of Application Tactics on the Urban Land Resources.Modern Finance and Economics, Vol, 24, 22-25.

Hui-yong Wang, Yan-bo Qu, Xiao-mei Zheng. (2007). Application of Primary Component Analysis in the Assessment of Land Ecological Security at Township Level. Journal of Anhui Agricultural Sciences, Vol ,35,4614 - 4617.

Jing Wang, Xiao-mei Shao. (2008). Methodologies of Intensive Land Use Research: Issues and Trend.Progress in Geography, Vol, 27, 68-74.

Ju-zhou Xu. (1999). Realistic View on Urban Land Use and Its Development.City Planning Review, Vol ,23,9-13.

Land and Natural Resources Information Center. (2006). Study on Land and Resources for Sustainable Development in China. Beijing: Geological Press.

Lu-hong Zhou, Zeng-lin Hong, Xu-ping Xue. (2009). Analysis on Intensive Land Use Potential in Old City Renovation Area of Daxing New District in Xi'an City. China Land Science, Vol ,23,49-57.

Tian-ming Zhu, Gui-shan Yang, Wei-zhong Su et al. (2009). Coordination Evaluation between Urban Land Intensive Use and Economic Society Development in the Yangtze River Delta.Resources Science, Vol, 31,1109-1116.

Sheng-he Liu, Jianmin Zhou. (2001). Western urban use study of theories and methods. Urban Planning Overseas, Vol ,1,17-19.

Statistical Bureau of Sichuan Province. (2003). 2003 Sichuan Yearbook. pp264-278.

Wei-dong Liu, Hua-bao Yuan. (1999). Urban Intensive Land Use--Change of Real Estate Development and Management Strategy.Journal of Tongji University (Social Science Edition), Vol ,10,56-61.

Wen-tao Li, Shu-kui Tan, Wen-xiong Wang. (2009). Empirical Study of Spatial-temporal Differences of Urban Land Use Intensity Based on DPSIR Model: A Case of Hubei Province. China Land Science, Vol,23,49-54.

Xian-wen Li, Pei Lin. (2001). The Theoretical Basis and Progress: Utility and Protection of the Farmer-land in Foreign and Home. Progress in Geography, Vol, 20, 305 312.

Xiu-ru Dong, Shui-lian Shi, Qiu-bing Wang. (2006). Dialectic Relations of Intensive Land Use and EcologicalEnvironment.Technology of Soil and Water Conservation, Vol, 3, 33-34.

Xin-wei Liu, Li-jun Zhang et al. (2006). Research on Intensive utilization of land resources in China. Beijing: Geological Press.

Xiong Ou, Chang-chun Feng et al. (2007). Application of Synergisticity Model in Urban Land-Use Potential Appraisal. Geography and Geo-Information Science, Vol, 23, 42.

Xiao-yan Wang, Liang-ji Deng, Hua-wei Zheng. (2008). An Evaluation of Urban Land Intensive Use and Influence Factors in Chengdu City. Scientific and Technological Management of Land and Resources, Vol, 25,69-73.

Xiao-bo Yang. (2008). Classic Case and Experimental Instruction of Urban Ecology, Beijing: Science Press, pp47-52.

Yao-bin Liu. (2007). Theoretical and Empirical Study on the Relationship Between Urbanization and Resources Environment.Beijing: China's Financial and Economic Press.

Ye Cheng, Jing Wang, Fan-hua Meng et al. (2003). Study on Land Use Zoning, Beijing: Geological Press.

Yin-liang Xu, Ning Hu. (2004). Research on Land Use During The Course of Urbanization in Shandong Province. Journal of Shandong Normal University (Natural Science), Vol. 19. 68-71. 
Table 1 . The index system of coordination on urban land intensive use and land ecological security

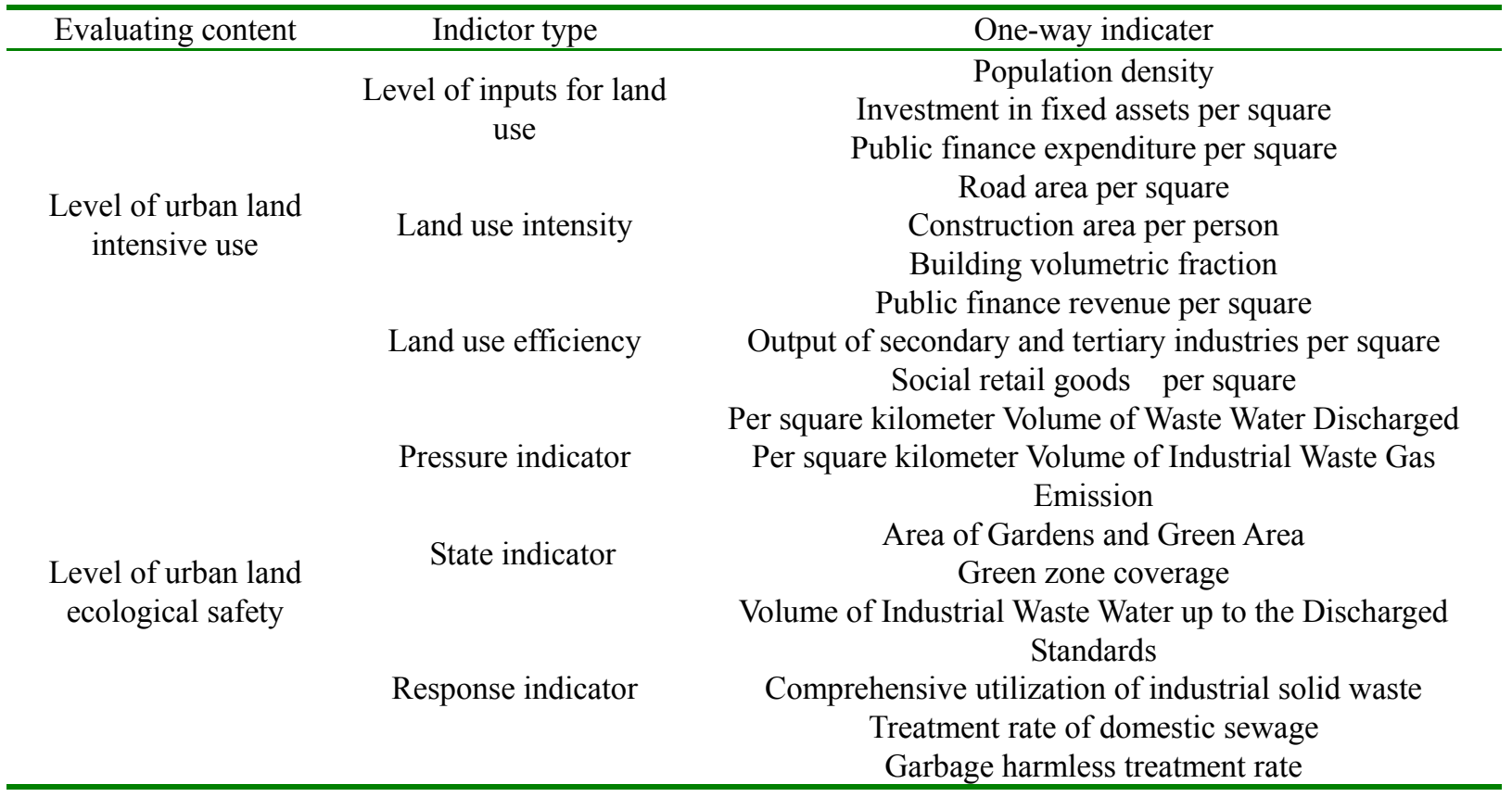

Table 2. The complex evaluation of urban land intensive use and land ecological security in Chengdu

\begin{tabular}{cccccc}
\hline Year & $\begin{array}{c}\text { Level of land } \\
\text { intensive use }\end{array}$ & $\begin{array}{c}\text { Level of land } \\
\text { ecological safety }\end{array}$ & Year & $\begin{array}{c}\text { Level of land } \\
\text { intensive use }\end{array}$ & $\begin{array}{c}\text { Level of land } \\
\text { ecological safety }\end{array}$ \\
\hline 1998 & -5.2241 & -4.3428 & 2003 & 0.0337 & 0.6131 \\
1999 & -4.6785 & -4.0737 & 2004 & 0.9967 & 2.2666 \\
2000 & -4.0670 & -4.1985 & 2005 & 3.0550 & 3.5766 \\
2001 & -3.0347 & -1.0868 & 2006 & 5.3874 & 3.5405 \\
2002 & -1.6279 & -0.4859 & 2007 & 9.1595 & 3.3338 \\
\hline
\end{tabular}

Note: Data of Construction area in 2005 was missing, calculating by annual average.

Table 3. The dynamic coordinated degree of city land intensive use and land ecological security in Chengdu from 1998 to 2007

\begin{tabular}{ccccccccccc}
\hline Year & 1998 & 1999 & 2000 & 2001 & 2002 & 2003 & 2004 & 2005 & 2006 & 2007 \\
\hline Dynamic coordinated degree & 8.99 & 17.56 & 25.39 & 32.33 & 38.35 & 43.51 & 47.92 & 51.69 & 54.92 & 57.71 \\
\hline
\end{tabular}

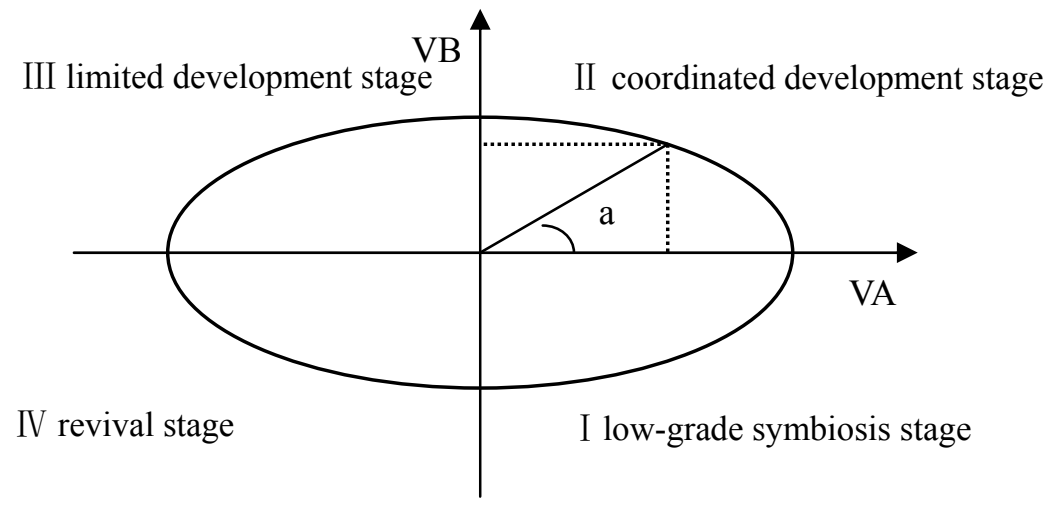

Figure 1. Evolutionary Cycle 


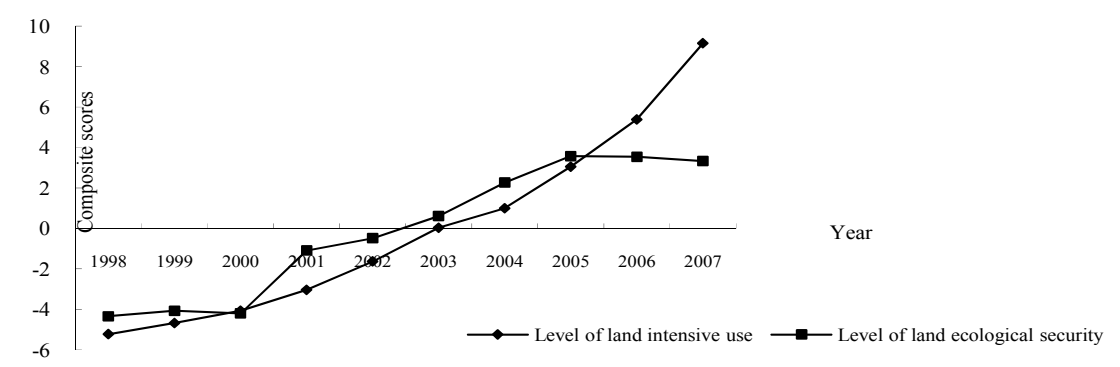

Fig.2 The complex evaluation of urban land intensive use and land ecological security in Chengdu 